- The fundamental principles of implantology

- How occlusal factors might influence implant success

- General considerations of implant case planning

- How to increase the chances of implant success by prescribing an ideal occlusion

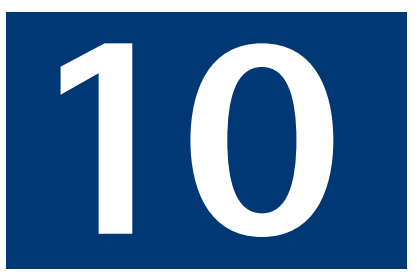

\title{
Good occlusal practice in the provision of implant borne prostheses
}

\author{
S. J. Davies, ${ }^{1}$ R. J. M. Gray ${ }^{2}$ and M. P. J. Young ${ }^{3}$
}

The increased use of endosseous dental implants means that many dentists will encounter patients with dental implants in their everyday practice. Dental practitioners might be actively involved in the provision of implant borne prostheses at both the surgical and restorative phases, or only at the restorative stage. This section is written for all dentists and aims to examine the subject of occlusion within implantology. It aims to provide guidelines of good occlusal practice to be used in the design of the prosthesis that is supported or retained by one or more implants. As implantology is a 'new' discipline of dentistry, there are fewer standard texts and this section, therefore, is much more extensively referenced than the subjects that have been considered to date.

This is the last section of this series.

\section{Even those general dental practitioners who are not implant providers are likely in the future to be responsible for the maintenance of implants}

${ }^{1 *} \mathrm{GDP}, 73$ Buxton Road, High Lane, Stockport SK6 8DR; P/T Lecturer in Dental Practice, University Dental Hospital of Manchester, Higher Cambridge Street, Manchester M15 6FH; ${ }^{2}$ Honorary Fellow, University Dental Hospital of Manchester, Higher Cambridge Street, Manchester M15 $6 \mathrm{FH}_{;}{ }^{3}$ Research Associate, Clinical Academic Group of Oral and Maxillofacial Sciences, University Dental Hospital of Manchester M15 6FH; BUPA Hospital, Whalley Range, Manchester M16 8AJ *Correspondence to: Stephen Davies, 73 Buxton Rd, High Lane, Stockport SK6 8DR

email:stephen.j.davies@man.ac.uk

\section{Refereed Paper}

๑ British Dental Journal 2002; 192: 79-88

\section{OSSEOINTEGRATION}

For osseointegration to occur predictably clinical guidelines have been developed to optimise success rates: ${ }^{1}$

- The implant must consist of a suitable biomaterial with appropriate surface properties

- Adequate vital bone must be present to support the implant

- A precise surgical fit must be achieved between the bone and the implant

- The implant must be inserted with a low-trauma technique to avoid overheating of the bone during preparation of the receptor site

- The implant should not be subject to functional loads during a healing period of 3-6 months (This traditional protocol is now being questioned).

Although these guidelines do not mention 'occlusion', once integrated, dental implants must be restored sympathetically with due regard to occlusion since unfavourable loading has been cited as a major cause of failure. This part of the series will present the factors that influence the occlusal schemes used for prostheses supported or retained by endosseous dental implants. Since relatively few studies have been designed with the sole aim of comparing different occlusal schemes, it is difficult to be certain what is the best occlusion for a given clinical situation. Current techniques and materials tend to be based on what has evolved over years of clinical practice and laboratory research. They are based on what is believed, rather than what is known, to be good occlusal practice in implantology.

'Osseointegration' is the biological process that results in a close structural relationship between vital bone and a dental implant. Successfully integrated and carefully loaded implants have been shown to be capable of being retained by the host tissues for many years. Osseointegration was first defined as 'the direct structural and functional connection between ordered living bone and the surface of a load carrying implant.' ${ }^{2}$ More recently this has been defined as 'a process whereby a clinically asymptomatic rigid fixation of alloplastic materials is achieved and maintained in bone during functional loading, ${ }^{3}$ Obviously, the significant difference between 'osseointegration' and the attachment of teeth to the alveolus is the absence of a periodontal ligament.

Although axons have been identified in peri-implant regions, their functional significance is not clearly understood. ${ }^{4}$ At present, the proprioceptive capability of restored implants is usually attributed to bone deformation of the periosteal mechanoreceptors on implant loading. ${ }^{5}$ Regardless of the precise mechanism for such proprioception, it has been shown that the 


\section{Implantology is based upon osseointegration}

\section{The absence of a periodontal ligament between an implant and the bone significantly reduces the patient's sensory perception of the occlusal load}

threshold of tactile sensitivity is approximately eight times less than that of natural teeth. ${ }^{6}$ In addition, the range of 'food-holding' forces for patients with implants is significantly higher than those for patients with natural teeth. ${ }^{7}$ When prescribing or modifying occlusal contacts for implant prostheses, it should be borne in mind that the patient's perception of occlusal irregularities and occlusal loads is much reduced and, therefore, should not be solely relied upon.

\section{CURRENT APPLICATION OF ORAL IMPLANTS}

The current application of implants is much more extensive than when implants were first utilised. In stark contrast to their initial applications [when predominantly only edentulous patients were treated with fixed dentures], implants are now inserted into:

- Partially dentate patients with a healthy or compromised periodontium.

- Posterior regions of the maxilla and mandible

- Sites in which the bone has been augmented.

In addition, many different types of prostheses may now be implant-supported:

- Fixed crowns

- Fixed bridges

- Fixed dentures

- Precision removable dentures

- Removable overdentures (mucosa and implant supported)

\section{IMPLANT SUCCESS}

Criteria for implant success have been outlined some years ago.

There should be an absence of:

- Mobility

- Associated radiolucency

- Pain

- Infection or iatrogenic neuropathies.

- Peri-implant vertical bone loss $<1.0 \mathrm{~mm}$ in the first year of loading $<0.2 \mathrm{~mm}$ per annum thereafter.

\section{IMPLANT SUCCESS VS IMPLANT SURVIVAL}

In recent years, 'implant survival' (implant retention at the end-point of the study) appears to be increasingly used when reporting treatment outcomes. ${ }^{8-17}$ This term might be mistakenly interpreted as being synonymous with implant success as defined above. ${ }^{18}$ Criteria for success are not always clearly defined and might be 'system specific'. Since implant survival is a crude measure of implant health, research that uses this term cannot be considered to be as meaningful as that which defines and measures implant success. Therefore, when evaluating clinical research studies, a critical appraisal must be made.

Despite numerous early studies that reported success rates in excess of 90\%, more recently lower success rates have been reported. ${ }^{19}$ This might be explained by the use of implants in more demanding circumstances, poor operator technique, or the use of an implant system with an unproven track record. A further factor might be the level of experience of the surgeons that provide implant treatment. ${ }^{20}$

\section{THE FAILING IMPLANT}

Whilst the efficacy of implants has been amply demonstrated for certain systems, fewer studies are available for any implant system to support their effectiveness in 'real life' studies where, for example, selection criteria might be more relaxed. ${ }^{21}$ As for all medical and dental treatments, we can expect the proven effectiveness of implants to be less than their proven efficacy. Against this background, it is important not only to define implant failure, but also to examine how it might be prevented.

A failing implant can be defined as one in which the criteria for success are not met. 'Periimplant' inflammation (peri-implantitis) presents a similar clinical picture to periodontal inflammation, with bone loss as a key feature. 'Perimucositis', has been reserved for soft tissue infection around an implant, whilst 'perimplantitis' implies accompanying bone loss (classification and review of implant failures). ${ }^{22-25}$

The 'failing' implant often presents as a chronic then terminal condition ultimately leading to implant exfoliation.

The stages of implant failure have been suggested to be (after Newman): ${ }^{26}$

1. Gingival inflammation

2. Gingival hypertrophy

3. Progressive deepening of pockets

4. Progressive attachment loss

5. Progressive bone loss

6. Change in microbial microflora

7. 'Osseo-disintegration' with mobility and periimplant radiolucency

8. Implant exfoliation

The suggested aetiological factors for implant failure are:

- Reduced host resistance

- Plaque accumulation

- Occlusal stress

- Systemic factors eg diabetes and smoking

Although a wide range of techniques has been employed to stabilise failing implants, it is recognised that the evidence to support these interventions appears poor at present. ${ }^{27}$

\section{CASE RESPONSIBILITY}

The determination of case responsibility is an important consideration for two reasons.

Firstly, implants can and do fail and the causes of failure are not completely understood.

Secondly, the provision of an implant borne restoration is often a team effort. If the same clinician carries out both surgical and restorative phases, the responsibility for design and execution of the treatment, together with an appropriate maintenance programme is unequivocal. 
However, when implant treatment is delivered as a 'team' (at one or more sites) the question of responsibility for implant failure becomes more complex and indeed more contentious. Failure under this regime may result in a debate which does the profession no credit.

When implant therapy is delivered by a 'team', close collaboration between the surgeon, restorative dentist and dental technician is essential. The surgeon must ask for guidance as to the optimal restorative implant location. Equally, the restorative dentist must appreciate the anatomical constraints when giving some guidance on the ideal position with regards to the proposed occlusal platform. The implant technician must have some concept of preferred occlusal schemes if appropriate occlusal contacts are to be incorporated into the implant supported prosthesis. In such situations, it is suggested that the most experienced member of the implant team becomes the 'team-leader', whether they be surgeon or restorative dentist.

The team leader must ensure that the joint treatment plan minimises the risk of implant failure. This is particularly important since the current evidence to support the efficacy of implant-rescue techniques is weak. The degree of responsibility will vary according to the experience of the team members, but the principle that a patient's treatment should not suffer through a lack of communication between the clinicians involved is paramount. The 'team leader' is responsible for ensuring that the appropriate communication exists to satisfy the needs of the case.

\section{OCCLUSAL OVERLOAD AS A CAUSE OF IMPLANT FAILURE}

It has been established that trauma from occlusion may be a factor in the aetiology of implant failure. ${ }^{22-28}$ It has been suggested that a radiological appearance of 'saucerisation or furrowing' is associated with occlusal overload (Fig. 1). ${ }^{29}$

Whereas the natural dentition is capable of physiologically adapting to traumatic occlusions, the absence of a periodontal ligament means that dental implants are more easily overloaded and this can to lead to implant failure. Left untreated, an overloaded implant will ultimately exfoliate. Remedial action must be speedily undertaken to redress the unfavourable loading conditions.

The causes of occlusal stress are numerous and include:

- Inadequate number of implants to support the prosthesis fitted

- Heavy occlusal contacts in centric occlusion

- Working-side interferences (as opposed to balanced contacts)

- Non-working side interferences

- Excessive buccal or lingual cantilever (the occlusal table too wide for the implant diameter) (Fig. 5b)

\section{The Surgeon's Tale}

'The implants were successfully integrated, but failed because

of excess loads'

or

The Restorative Dentist's Tale

'The implants were poorly integrated and so failed under normal masticatory loads'

eitherway

\section{The Patient's Tale \\ 'My implants have failed !'}

\section{TECHNIQUE}

Recommendations for occlusal schema for implant supported prostheses

It is the nature of osseointegration that determine the features of an 'ideal' occlusion for an implant supported prosthesis.

The fundamental nature of osseointegration (no periodontal ligament) means that proprioceptive and aptaptive potential is less than with natural teeth:

- The implant is rigidly attached and will move or intrude much less

- Although connections to the central nervous system are believed to exist, it is accepted that proprioception is reduced

- An implant cannot undergo orthodontic movement

An ideal occlusal scheme for fixed implant supported prostheses has been recommended: ${ }^{30}$

- A centric occlusion 'cusp to central fossa' contact which is light

- An ideal anterior guidance: that is canineguidance or group-function; no posterior interferences

- Axial loading of the implants

Historically, it has been recommended that non-axial loads should be dissipated by the use of inter-implant splinting, by means of bars or fixed-beam structures, and 'double-construction' techniques. However, in recent years this principle has been questioned ${ }^{31}$ and multiimplant cases are now being restored as multiple, non-splinted, single teeth implants. This approach, however, is a recent development and the evidence base is correspondingly light. As it is widely acknowledged that the bone of the posterior maxilla is poor in quality, the use of nonsplinted, multiple implants restored with fixed prostheses in this region is considered to carry a greater risk of failure. Careful loading in the posterior regions seems especially important to sustain acceptable implant success rates.

\section{TO CONFORM OR TO RE-ORGANISE?}

The decision to provide an occlusion in 'an implant case', either conforming to the pre-

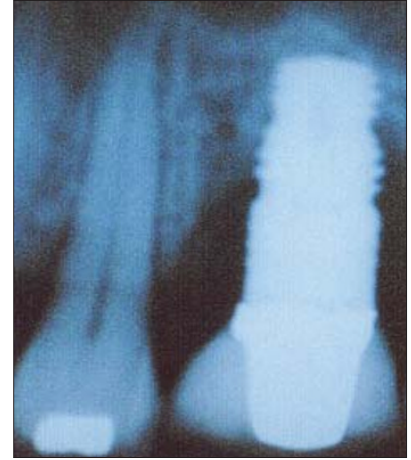

Fig. 1 A possible sign of occlusal overload: 'funnelling' or 'saucerisation'.

The absence of a
periodontal
membrane is believed
to be the reason why
endosseous implants
appear to tolerate
non-axial loads
poorly


existing occlusion or re-organising the occlusion, will be made in exactly the same manner as in any other restoration treatment plan. This decision-making process is described earlier.

Two guidelines are paramount:

- If it is possible to follow the conformative approach this is the safest route

- If an occlusion is to be re-organised, establishing and recording Centric Relation is the essential first step.

\section{$\mathrm{E}$ = Examine \\ D = Design \\ $\mathrm{E}$ = Execute \\ $\mathrm{C}=$ Check}

\section{CLASSIFICATION OF OSSEOINTEGRATED PROSTHESES}

The key features of an appropriate occlusion will in part depend upon the type of prosthesis. The different types of prostheses will be considered under the following classification:

- Single-tooth implant

- Full-arch, implant supported prosthesis

- Free-standing, fixed-prosthesis

Kennedy classes I, II, III, IV

- Implant-retained overdenture

- Implant \&t tooth-retained, fixed-prosthesis

\section{Single tooth replacement by implant retained crown}

The single, anterior tooth implant is now an accepted and a highly predictable means of tooth replacement. Until recently, molar tooth replacement by an endosseous dental implant was considered contra-indicated. Prior to the development of 'wide-diameter' implants, molars were restored using two narrow implants. Recent studies indicate that similar success rates can be expected for double or single implant molar replacements. ${ }^{32-34} \mathrm{~A}$ poor occlusal scheme is likely to increase the risk of implant failure in the posterior region, since the chewing forces in this region greatly exceed those in the anterior region, and because bone quality is poorer.

\section{IDEAL OCCLUSION FOR SINGLE TOOTH IMPLANT}

- Light load (infra-occlusion by $30 \mu \mathrm{m}$ ) under heavy clenching

- Occlusal force directed down the long axis of implant

- Light or no occlusal contact during excentric excursions.

Discussion of requirements of 'ideal' occlusion for single tooth implant (Fig. 2)

1. The occlusion required for the single tooth replacement is similar, but not identical, to the natural dentition. In centric occlusion, the implant supported crown should have a clearance of $30 \mu \mathrm{m}$. This clearance is important since the natural teeth can be intruded in their sockets under heavy loads whereas the implant retained prosthesis will not intrude. Any clinician who is used to adjusting conventional crown and bridgework using shimstock ( thickness $8 \mu \mathrm{m}$ ) will recognise that
$30 \mu \mathrm{m}$ is a significant clearance. Failure to build in this appropriate occlusal clearance would expose the implant-retained fixedprosthesis to excessive forces under heavy loading conditions. Unfortunately, the patient cannot be relied upon to report that an implant supported crown is 'high' because the absence of a periodontal membrane means that there is limited proprioception in the implant-alveolar bone system.

2 Endosseous implants are best able to withstand forces that are directed down the long axis of the implant, because of the absence of the periodontal ligament sling. This requirement is not purely a consideration in the restorative phase of the treatment, the placing of an implant should wherever possible take account of the eventual occlusal loading.

3 Light excentric contacts are a vital requirement to avoid non-axial loading.

It is possible to 'hide' the implant within the natural occlusion by slight infra-occlusion, so the single tooth implant can easily be protected from mechanical overload. Adjacent natural teeth should be 'recruited' to provide proprioceptive protection from excess loads.

\section{Full-arch, implant supported prosthesis}

Two occlusal schemes have been described and recommended for the restoration of full-arch implant supported, fixed- prostheses: ${ }^{35}$ 1. Mutually protected occlusion (MPO) 2. Lingualized occlusion (LO)

\section{a) Mutually protected occlusion( MPO)}

This concept recommends that in centric relation there is only posterior tooth contact. The maxillary palatal cusps and mandibular buccal cusps should occlude with their opposing occlusal fossae. Thus, anterior teeth positively disclude the posterior teeth in all excentric excursions, protecting the posterior teeth (or implants) from harmful lateral forces. This type of mutually protected occlusion has been reported to be the most efficient in terms of mastication, combined with what is widely regarded to be the optimal aesthetic appearance. This 'gnathological' scheme is believed to closely represent the "perfect' natural occlusion.

Whereas most of us can describe this type of occlusion, to fabricate, fit and monitor such an occlusion requires considerable laboratory and technical expertise, substantial clinical skills and ample chair-side time. MPO requires that a large number of contacts between the posterior teeth should occur simultaneously. The contacts between the back teeth should be tripodal cuspto-fossae. Analysing and modifying such complex contacts is generally considered very difficult in full-arch implant supported prostheses. Chairside occlusal equilibriation will almost always be necessary.

Guideline: Avoid non-axial loading whenever possible. Shallow central fossae with tripodal cuspal contacts should be attained. The presence 
of ridge-lapping should be minimised whenever possible and the distal length of a cantilever has been empirically recommended between 10 and $20 \mathrm{~mm}$. More recently, it has been suggested that the optimal distal cantilever is in the region of just $7 \mathrm{~mm}$. When exceeding this length, clinicians should carefully consider the number, location and precise arrangement supporting implants. ${ }^{36}$

\section{b) Lingualized occlusion (LO)}

Since it is acknowledged that MPO is difficult and time-consuming to fabricate, fit and maintain, alternative occlusal schemes have been proposed. Specifically, 'lingualized occlusion' has been recommended for the restoration of full-arch dental implants. The aims are the same but the major benefits of this occlusal scheme are the comparative simplicity with which it can be established and maintained, and its ability to direct masticatory loads axially onto the supporting dental implants.

The key feature is the arrangement of the posterior teeth so that only the maxillary palatal cusps (hence: 'lingualized' occlusion; or should it have been called 'palatalised' occlusion?) occlude with shallow mandibular central fossae. There is no contact between the mandibular buccal cusp and palatal maxillary cusps which might result in a inclined (non-axial) contact. Laboratory fabrication time is reduced and this scheme represents a posterior occlusion that can be more readily observed in both the laboratory and clinical environments thereby enabling any unfavourable occlusal contacts to be identified and corrected more easily.

A very minor disadvantage of lingualized occlusion is the creation, by definition, of a slight buccal space between the buccal cusps of the mandibular teeth and their maxillary counterparts. However, since this spacing occurs in the posterior region of the arches, the aesthetic implications are minimal.

Guideline: Avoid non-axial loading whenever possible. Shallow mandibular central fossae with maxillary palatal cuspal contacts should be attained. The presence of ridge-lapping should be minimised whenever possible and the length of a cantilever should not extend further than $7 \mathrm{~mm}$ beyond the most distal implant (See later for an explanation of ridge lapping).

\section{Free-standing, fixed-bridges ( Kennedy Classes I -IV inclusive)}

\section{a) Kennedy Class I}

Guideline: In these bilateral free end saddle cases both posterior sections of the arch are restored with osseointegrated bridges. The anterior guidance will be provided by the natural dentition as long as the implant supported bridges are designed to allow adequate posterior disclusion. There is a conflict in the design of these bridges, which is impossible to resolve. On the one hand there is an indication to make the occlusal stops on the posterior bridges lighter by

\begin{tabular}{|c|c|}
\hline Fig. 2 & Predictability of success for a single tooth implant \\
\hline Guidelir & $\begin{array}{l}\text { - Ideal Case } \\
\text { - } \text { - Aetiology of tooth loss = acute trauma } \\
\text { - Vertical bone loss = nil } \\
\text { - Adequate bone width } \\
\text { - Adequate posterior occlusion } \\
\text { - Absence of prematurities in CR } \\
\text { - Canine-guided disclusion } \\
\text { - Protrusive contact should be evenly distributed on the incisors } \\
\text { - Classlincisor relationship anterior clearance } 30 \mu m \text { in centric occlusion } \\
\quad \text { Predicted Success is Very High } \\
\text { Conform to existing occlusion which is atraumatic (The Conformative Approach) }\end{array}$ \\
\hline & $\begin{array}{l}\text { - Non-Ideal Case } \\
\text { - } \text { - Aetiology of tooth loss: root fracture (previously post-retained crown) } \\
\text { - Vertical bone loss = nil, } \\
\text { - Adequate bone width. } \\
\text { - Severe cuspal attrition of all four canines } \\
\text { - Multiple teeth with mirror-faceting } \\
\text { - Reduced vertical dimensions } \\
\text { - Posterior occlusion exhibits very wide based occlusal contacts } \\
\text { - Edge to edge incisor relationship } \\
\text { - Group function exhibited in lateral excursion } \\
\text { - No posterior disclusion in protrusive excursions } \\
\quad \text { Predicted Success is Questionable }\end{array}$ \\
\hline $\begin{array}{l}\text { Guidelir } \\
\text { implant } \\
\text { (ie the r } \\
\text { patient } \\
\text { surface }\end{array}$ & $\begin{array}{l}\text { isting occlusion is unfavourable and may have contributed to the loss of this tooth, so } \\
\text { tment is contra-indicated until the natural occlusion is changed to being a more ideal one } \\
\text { yanised approach ). The alternative is to proceed with implant treatment after making the } \\
\text { e that the implant will be placed into a comparatively hostile environment.. Certainly if tooth } \\
\text { continues, the implant will become highly susceptible to overload. }\end{array}$ \\
\hline
\end{tabular}

about $30 \mu m$ than those in the remaining natural teeth. On the other hand, (given that there is general agreement that it is more ideal that the back teeth contact harder than the front teeth) this will not be possible if the posterior occlusion is exclusively provided by the implant supported bridges. It is not unusual for clinicians to have such issues to reconcile. The best treatment outcome is likely to be provided by those clinicians who realise that there is a danger of trauma from occlusion and so will carefully monitor the situation.

\section{b) Kennedy Class II}

Guideline: This clinical situation (unilateral free end saddle) can be regarded as a very favourable application for a fixed prosthesis because the natural teeth will provide the occlusion; whilst the contralateral unilateral free end saddle can be restored with implant supported bridgework that has $30 \mu \mathrm{m}$ clearance.

\section{c) Kennedy Class III}

Guideline: Where there are bounded posterior saddles the use of implants is again ideal because the adjacent natural teeth that bound the edentulous space will allow the construction of the restorations with the $30 \mu \mathrm{m}$ clearance; and the anterior teeth will provide the ideal anterior guidance. 


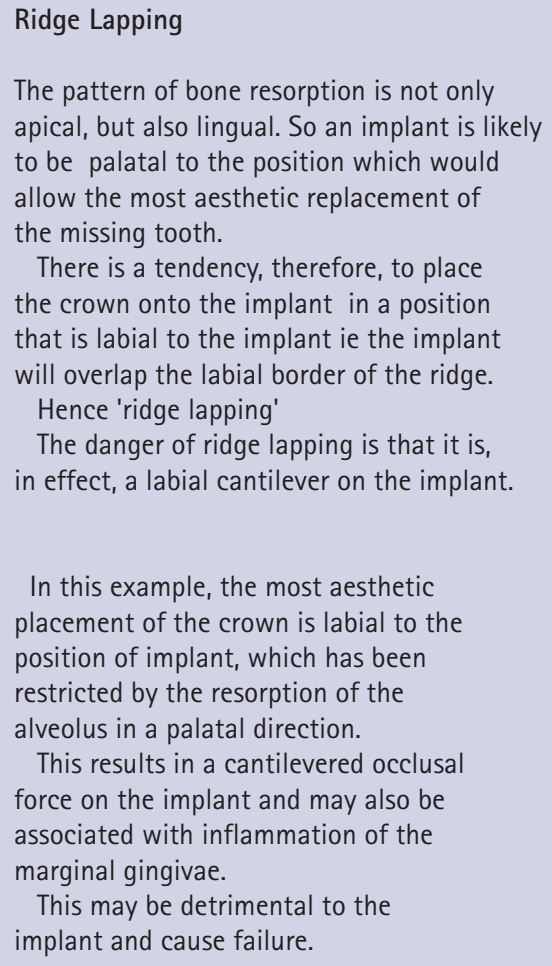

The pattern of bone resorption is not only apical, but also lingual. So an implant is likely to be palatal to the position which would allow the most aesthetic replacement of the missing tooth.

There is a tendency, therefore, to place the crown onto the implant in a position that is labial to the implant ie the implant will overlap the labial border of the ridge. Hence 'ridge lapping'

The danger of ridge lapping is that it is, in effect, a labial cantilever on the implant.

In this example, the most aesthetic placement of the crown is labial to the position of implant, which has been restricted by the resorption of the alveolus in a palatal direction.

This results in a cantilevered occlusal force on the implant and may also be associated with inflammation of the marginal gingivae.

This may be detrimental to the implant and cause failure.

Ideal ridge form for the implant to support aesthetic crown

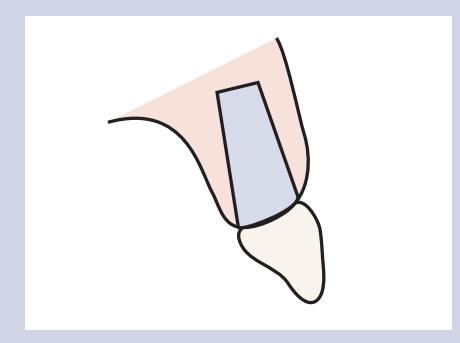

Resorbed ridge form resulting in excessive ridge lapping (for aesthetic reasons)

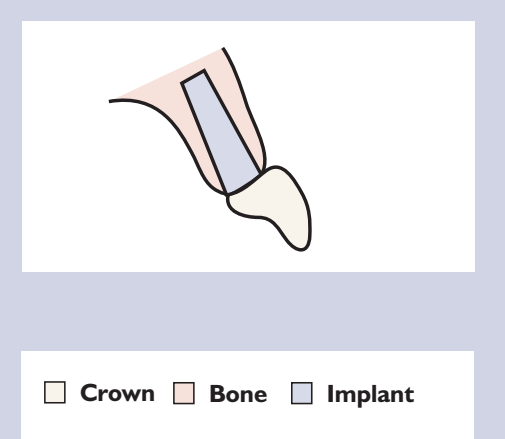

\section{d) Kennedy Class IV}

Guideline: This is an anterior bounded saddle. When there is as a large span (for example UR4 (14) to UL4(24) it is very difficult to restore with a fixed bridge because of the excessive torque that is a result of the cantilever. In contrast, the insertion of four to six anterior implants can easily and predictably treat this situation. The implant-supported Kennedy Class IV bridge must provide an appropriate anterior guidance which achieves posterior disclusion, and a shallow anterior guidance is recommended. In addition, is advisable to prescribe slightly greater freedom in centric occlusion than for natural anterior teeth.

\section{Overdentures}

Overdentures may be used for both maxillary and mandibular edentulous cases.

Guideline: In the upper arch it is usual to use a minimum of four implants for denture retention and full palatal coverage is employed for additional support and retention. However, in view of the generally softer bone in the maxilla than in the mandible, six implants would be preferable, in order to reduce the functional load on each implant. In the mandible, two implants may be sufficient. The occlusion recommended in either denture is fully balanced lingualized occlusion.

The particular problem of designing an occlusion between a mucosa supported upper complete denture and an implant retained lower complete denture are discussed under 'New combination syndrome' (Section 3C(iii) of the section on Good Occlusal Practice in Removable Prosthodontics).

\section{Implant and tooth-retained, fixed- prosthesis}

The concept of linking natural teeth to implants to support a fixed bridge has stimulated considerable debate and research. It is widely accepted that this situation is less than ideal since it requires rigid bone-anchored implant(s) to be joined to a relatively mobile natural tooth. The reason why it is extremely difficult to design an ideal occlusion for a fixed bridge that is supported in this way is that the bridge would be a rigid link between two totally different attachments to bone. Reaction to occlusal load is dependant upon the form of the attachment to bone. Since the attachments of teeth and implants are so different, the reaction to occlusal load is bound to differ; and this can have an adverse effect on the attachments and/or the prosthesis.

The IMZ ${ }^{\circledR}$ implant system (FRIADENT AG, Manheim, Germany) possesses a compressible component that reduces the impact of an occlusal force to the supporting implant. ${ }^{37}$ It has been suggested that this 'stress-breaking' feature lends itself to linkage with natural teeth. However, intrusion of the natural supporting tooth has been reported when $\mathrm{IMZ}^{\circledR}$ implants in combination with natural teeth are used to support fixed bridges. ${ }^{38}$ Although this system seems to overcome the inherent problems of linking teeth to implants, it is widely acknowledged that the scientific evidence for this is limited at present. As a consequence, fixed prostheses supported by teeth and implants should be avoided whenever possible.

\section{CONSIDERATIONS OF CASE PLANNING}

The relationship between the occlusion and the implant/bone that will support it is extremely important. Restoration by the provision of implant supported prosthesis presents a challenge, because the clinician has the opportunity to:

- Decide the size and shape of the occlusal table

- Choose the number, position, size and orientation of the implants

- Modify the quantity and architecture of the bone.

These variations are not, of course, without limit and there will be constraints imposed by the patient's condition. Nevertheless the many different types and designs of prostheses, the considerable number of available implant systems and the possibility of bone augmentation offer considerable choice for each and every case.

These choices can only be enjoyed by patients of those dentists who plan ahead.

This large number of variables that exists within these design options emphasise the need 

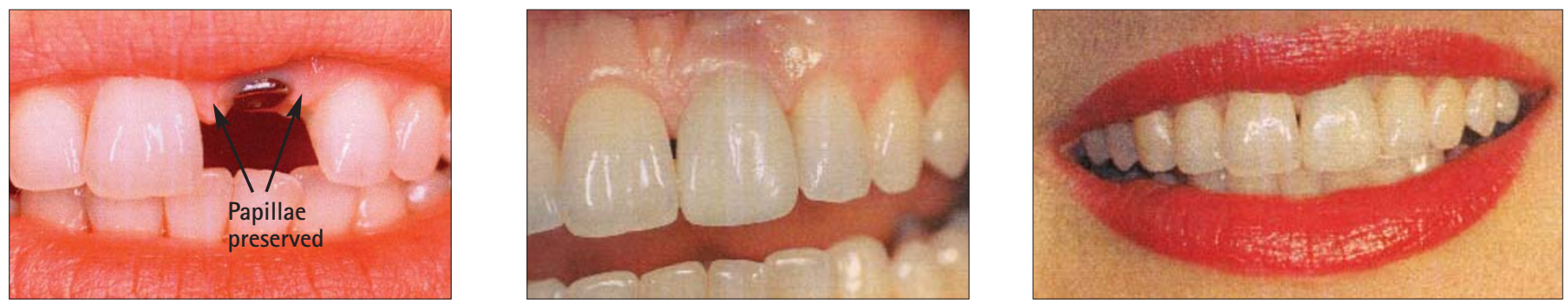

Fig. 4a-c If the implant is inserted before vertical bone loss has occurred, a normal clinical crown length will result (see Fig. 6a)

for careful treatment planning and communication within the treatment team (surgeon, restorative dentist, laboratory technician and maybe hygienist and / or general dental practitioner). The process follows the previously described EDEC principle.

Presented below are some of the variables and their relationship to occlusion.

\section{Relationship between occlusal table and implant diameter}

Cantilevered forces may result from extending the prostheses beyond where the implants are located or arise more subtly in the form of ridge-lapped fixed prostheses (Fig. 3). Both are a source of non-axial loading and, therefore, potentially risk implant failure. Clearly, the relationship between implant diameter and occlusal dimensions are linked to non-axial loading (Fig. 4 and 5a,b). ${ }^{39-40}$ Non-axial loading is to be avoided if at all possible.

If the ridge is narrow, because of resorption, the solution may be:

- Not only a narrow implant, but also a narrow crown

- Bone augmentation or bone manipulation, to allow a wider implant to be inserted.

\section{Ideal occlusal morphology}

Provide an occlusion which is:

- Balanced occlusion with low cuspal angles and freedom in centric occlusion ${ }^{41}$

- Complimentary to the existing occlusion

- Achievable (lingualised occlusion may be easiest)

- Free of any non-axial forces (ie no inclined contacts and posterior interferences).

\section{The significance of implant length-crown} length ratio

In simple terms, a crown length to implant length ratio of 1:2 is ideal. To achieve this, early implant placement before vertical bone height has been lost is recommended. Immediate, or delayed implant insertion (at 6 to 12 weeks after extraction in the absence of bone pathology) usually facilitates the optimal crown/implant ratio. In practice, this means that the implant option needs to be considered before the extraction of a tooth.

With increasing vertical bone loss the implantcrown ratio will become progressively less favourable (Fig. 6a-c), not just in terms of loading but also in terms of aesthetic results and hygiene maintenance. Once the implant-crown ratio approaches 1:1 a removable prosthesis should be considered. Although the relationship between the head of the implant and the occlusal plane has obvious loading implications which are likely to affect implant success rates, there are no published studies in this area.

Guideline: Maximise the implant to crown ratio when anatomically possible. With significant vertical bone loss, a fixed prosthesis may not be feasible unless pre-implant bone grafting is acceptable to re-establish favourable inter-arch vertical relationships.

\section{The site and nature of the implant bed}

It is known that for osseointegration to occur predictably certain conditions must be met:

- The implant must consist of a suitable biomaterial with appropriate surface properties

- Adequate vital bone must be present to support and integrate with the implant

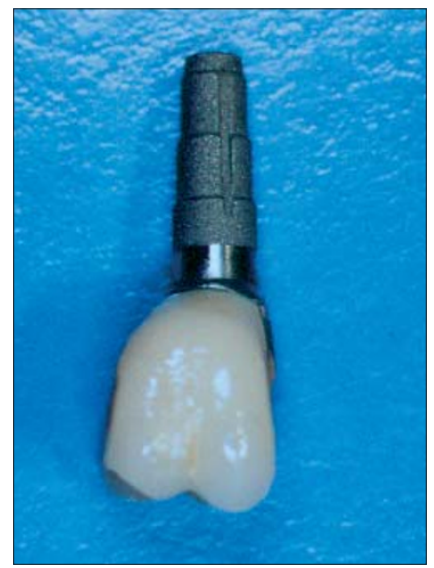

Fig. 5a Buccal view of failed implant that was supporting an occlusal table with a slight distal cantilever

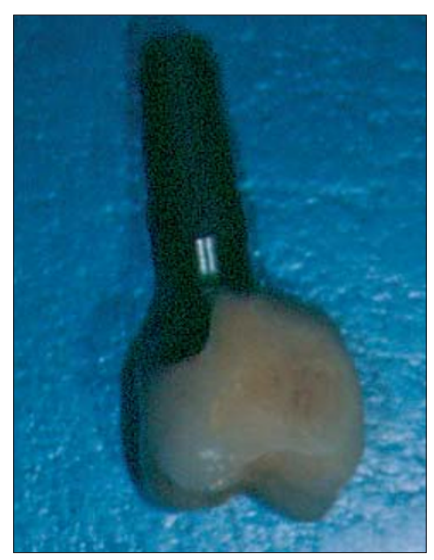

Fig. $5 b$ Distal view of the same implant supporting crown with excessive buccal cantilever. Unsurprisingly this implant dramatically failed.

Fig. 6 a-c Illustration of
how the implant to
crown ratio becomes
progressively worse
(loading and
aesthetics) with
increasing vertical
bone loss. (Yellow line
is the bone level and
the red line is the
gingival margin)

a)

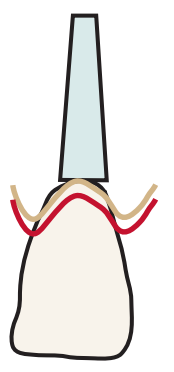

b)

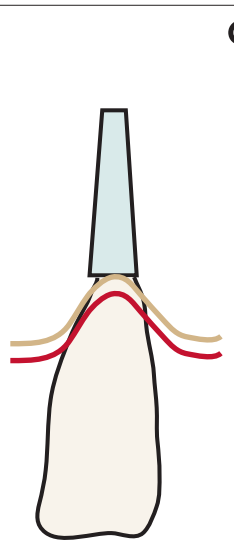

c)

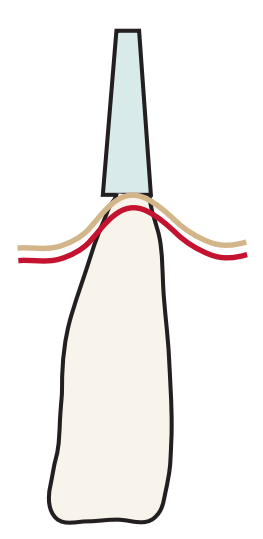


Summary of occlusal guidelines:

- Select the widest diameter implant

- Provide a vertical emergence profile with no ridge lapping to avoid nonaxial loading

- In narrow ridges consider a removable prosthesis, ridge augmentation, or abandoning implant treatment

- The occlusal table should be designed not to overload the bone-implant interface

- A precise surgical fit must be achieved between the bone and the implant

Clinical studies and experience have shown that implants placed into the posterior maxilla can be expected to show lower success rates, ${ }^{19,42}$ this may be caused by the potentially higher occlusal loads at the back of the mouth. Equally, an implant site that has been augmented (regardless of the material or technique used) can be expected to possess a reduced ability initially to withstand occlusal load. This effect might be permanent or temporary, depending upon the material used and the ability of that material to bond with or become replaced by vital bone.

Guideline: The ability of the implant bed to support occlusal load is dependant upon:

- Site (occlusal load potentially increases towards the back)

- Quality of supporting bone (stable autogenous bone with no augmentation is the gold standard').

\section{The importance of monitoring of occlusal load}

Since osseointegrated implants cannot move by nature of their relationship with bone, there is a considerable temptation to consider that restored implants require little if any monitoring. However, the nature of occlusal contacts and relationships can change as a result of many factors including tooth and prosthesis wear (Fig. 7), loss of teeth or implants, and mucosal atrophy. ${ }^{43}$

Guideline: Regularly evaluate the occlusal relationships of the implant supported prosthesis (at short intervals, typically 3-6 months). The provision of any treatment that has the potential to change the occlusion anywhere in the mouth should be the trigger to check the
Fig. 7 Prosthesis wear. Six years of
use have severely worn this implant supported denture. Compare the worn denture (Fig. 7a) against the spare denture (Fig. 7b) which was made at the same time. occlusion of an implant supported prosthesis. Accurate occlusal records of the starting point are extremely helpful.

\section{Pre-treatment examination and case 'work up'}

Not all cases will need all of the stages laid out below. These stages are presented as guidelines to ensure that the occlusion provided by a prosthesis supported by implants is well tolerated by the patient.

\section{Examination}

A short examination of the patient's articulatory system (TMJ, muscles, occlusion) is needed to diagnose any pre-existing TMD. This will include any signs of an active parafunction (tongue scalloping and cheek ridging). In particular, a note would be made of any evidence that occlusal factors contributed to the loss of teeth for which implant treatment is being considered. This could alter the treatment plan considerably.

A qualitative and quantitative assessment of the potential implant bed will influence the type of the prosthesis and the occlusal table that it can provide.

\section{Case 'work up'}

Study models mounted on a semi-adjustable articulator after facebow record will make it much simpler to examine the existing occlusion and to design an appropriate occlusal scheme

A diagnostic wax-up or pre-implant diagnostic prosthesis will help the restorative clinician and the laboratory technician plan the eventual prosthesis. It will also be an aid in the construction of any temporary or provisional restorations.

A surgical stent is a device that enables the ideal position of the implants to be visualised at the surgical phase of treatment. Its use is more than simply a surgical aid, it embodies the principle that the position of the implants should (within the physical constraints of the alveolar bed) be determined by the aesthetic and occlusal objectives of the final restorations. A diagnostic wax up (see section on Good Occlusal Practice in Advanced Restorative Dentistry) will greatly facilitate the construction of a useful surgical splint. The principle that the position of the implants will be determined before the surgical appointment and by factors including the aesthetic and occlusal objectives of the treatment plan is paramount. 
1. Buser D, Dula K, Belser U, Hirt H P, Berthold $\mathrm{H}$. Localised ridge augmentation using guided bone regeneration 1. Surgical procedure in the maxilla. Int J Period \& Rest Dent 1993; 13: 29-45

2. Adell R, Lekholm U, Rockler $B$ Branemark PI. A 15-year study of osseointegrated implants in the treatment of the edentulous jaw. Int J OralSurg 1981; 10: 387-416.

3. Zarb G. Osseointegration: a requiem for the periodontal ligament? Int Period \& Rest Dent 1991: 11: 88-91.

4. Weiner S, Klein M, Doyle J L, Brunner M Identification of axons in the periimplant region by immunohistochemistry. Int J Oral Maxillofac Implants 1995; 10: 689695.

5. Jacobs R, van Steenberghe D. Comparison between implantsupported prostheses and teeth regarding passive threshold level. Int J Oral Maxillofac Implants 1993; 8: 549554.

6. Hammerle $\mathrm{CH}$, Wagner D, Bragger U et al. Threshold of tactile sensitivity perceived with dental endosseous implants and natural teeth. Clin Ora Implants Res 1995: 6: 83-90.

7. Trulsson M, Gunne HS. Food-holding and biting behavior in human subjects lacking periodontal receptors. J Dent Res 1998; 77: 574-582.

8. Rosen PS, Summers R, Mellado J R et $a l$. The bone-added osteotome sinus floor elevation technique: multicenter retrospective report of consecutively treated patients. Int J Oral Maxillofac Implants 1999: 14: 853-858.

9. Keller E E, Tolman D E, Eckert SE. Maxillary antral-nasal inlay autogenous bone graft reconstruction of compromised maxilla: a 12-year retrospective study. Int J Oral Maxillofac Implants 1999; 14: 707-721.

10. Mericske-Stern R, Perren R, Raveh Life table analysis and clinical evaluation of oral implants supporting prostheses after resection of malignant tumors. Int J Oral Maxillofac Implants 1999; 14: 673-680

11. Lekholm U, Gunne J, Henry P, Higuchi $\mathrm{K}$, Linden U, Bergstrom C, van Steenberghe D Int Survival of the Branemark implant in partially edentulous jaws: a 10-year prospective multicenter study. J Oral Maxillofac Implants 1999; 14: 639-645.

12. Balshi TJ, Wolfinger G J, Balshi SF. Second Analysis of 356 pterygomaxillary implants in edentulous arches for fixed prosthesis anchorage. Int J Oral Maxillofac Implants 1999; 14:398-406

13. Froum SJ, Tarnow D P, Wallace SS, Rohrer M D. Cho SC. Sinus floor elevation using anorganic bovine bone matrix (OsteoGraf/N) with and withou autogenous bone: a clinical, histologic radiographic, and histomorphometric analysis. Part 2 of an ongoing prospective study. Int J Periodontics
Restorative Dent 1998: 18:528-543.

14. Ivanoff C J, Grondahl K, Sennerby L, Bergstrom C, Lekholm U. Influence of variations in implant diameters: a 3- to 5 -year retrospective clinical report. In J Oral Maxillofac Implants 1999; 14 : 173-180.

15. Morris H F, Ochi S Hydroxyapatitecoated implants: a case for their use. $J$ Oral Maxillofac Surg 1998; 56: 13031311.

16. Karlsson U, Gotfredsen $K_{1}$ Olsson CA 2 year report on maxillary and mandibular fixed partial dentures supported by Astra Tech dental implants. A comparison of 2 implants with different surface textures. Clin Oral Implants Res 1998; 9: 235-242

17. Watson R, Marinello C, Kjellman O, Rundcrantz T, Fahraeus J, Lithner B. Do healing abutments influence the outcome of implant treatment? A three-year multicenter study. $J$ Prosthet Dent 1998: 80: 193-198.

18. Albrektsson T, Zarb G A, Worthington $P$ Eriksson A R. The long-term efficacy of currently used dental implants: a review and proposed criteria of success. Int J Oral Maxillofac Surg 1986; 1: 11-25.

19. Watson CJ, Tinsley D, Ogden A R Russell J L, Mulay S, Davison E M. A 3- to 4-year study of single tooth hydroxylapatite coated endosseous dental implants. BrDent J 1999; 187 90-94.

20. Preiskel H W, Tsolka P. Treatment outcomes in implant therapy: the influence of surgical and prosthodontic experience. Int J Prosthodont 1995: 8:273-279.

21. Weyant R J. The case for clinica registries. In Trotman C A, McNamara J A. (eds) Orthodontic treatment: outcome and effectiveness. 1st ed pp 319-343. Ann Arbor: University of Michigan.

22. el Askary A S, Meffert R M, Griffin T Why do dental implants fail? Part I. Implant Dent 1999; 8: 173-185.

23. Esposito M, Lausmaa J, Hirsch J M Thomsen P. Surface analysis of failed oral titanium implants. JBiomed Mater Res 1999; 48: 559-568.

24. Esposito $M_{\text {, Thomsen }} P_{\text {, Ericson }} L E_{\text {, }}$ Lekholm U. Histopathologic observations on early oral implant failures. Int J Oral Maxillofac Implants 1999; 14: 798-810.

25. O'Mahony A, Spencer $P$. Osseointegrated implant failures. JIrDentAssoc 1999: 45: 44-51.

26. Newman 1988 Newman M J, Flemmig FT. Periodontal considerations of implants and implant associated microbiota. J Dent Educ 1988; 52: 737

27. Esposito M, Hirsch J, Lekholm U, Thomsen P. Differential diagnosis and treatment strategies for biologic complications and failing oral implants: a review of the literature. Int J Oral Maxillofac Implants 1999; 14 473-490

28. Isidor F. Histological evaluation of peri- implant bone at implants subjected to occlusal overload or plaque accumulation. Clin Oral Implants Res 1997: 8: 1-9.

29. Palmer R, Palmer P, Howe L. Dental implants: Part 10. Complications and maintenance. Br Dent J 1999: 187 . 653-658.

30. M Norton. Fixed bridge rehabilitation. In M.Norton Dental Implants: a guide for the general practitioner. 1st ed. pp 81-104. London: Quintessence Publishing Co Ltd,1995.

31. Muftu A, Chapman R J. Replacing posterior teeth with freestanding implants: four-year prosthodontic results of a prospective study. JAm DentAssoc 1998; 129 : 1097-1102.

32. Bahat $\mathrm{O}$, Handelsman M. Use of wide implants and double implants in the posterior jaw: a clinical report. Int J Oral Maxillofac Implants 1996; 11:379386.

33. Balshi TJ, Hernandez R E, Pryszlak M C Rangert B A comparative study of one implant versus two replacing a single molar. Int J Oral Maxillofac Implants 1996: 11:372-378.

34. Schwartz-Arad D, Samet N. Single tooth replacement of missing molars: a retrospective study of 78 implants. J Periodontol 1999: 70: 449-454.

35. Reitz J V. Lingualized occlusion in implant dentistry. Quintessence Int 1994: 25: 177-180.

36. Rodriguez A M, Aquilino S A, Lund PS, Ryther J S, Southard TE. Evaluation of strain at the terminal abutment site of a fixed mandibular implant prosthesis during cantilever loading. J Prosthodont 1993 ; 2: 93-102.

37. Chapman R J, Kirsch A Variations in occlusal forces with a resilient internal implant shock absorber. Int J Oral Maxillofac Implants 1990; 5: 369-374.

38. Garcia LT, Oesterle LJ. Natural tooth intrusion phenomenon with implants: a survey. Int J Oral Maxillofac Implants 1998; 13: 227-231.

39. Weinberg LA, Kruger B. An evaluation of torque (moment) on implant/prosthesis with staggered buccal and lingual offset. Int $J$ Periodont Restor Dent 1996; 16: 252265.

40. Weinberg LA Reduction of implant loading using a modified centric occlusal anatomy. Int J Prosthodont 1998; 11: 55-69.

41. Kaukinen J A, Edge M J, Lang B R. The influence of occlusal design on simulated masticatory forces transferred to implant-retained prostheses and supporting bone. J Prosthet Dent 1996; 76: 50-55.

42. Jaffin RA, Berman CL. The excessive loss of Branemark implants in type IV bone: a 5-year analysis. J Periodontol 1991:62:2-4

43. Dario LJ. How occlusal forces change in implant patients: a clinical research report. JAm Dent Assoc 1995; 126: 1130-1133. 


\section{The completed list of guidelines of good occlusal practice}

1 The examination of the patient involves the teeth, periodontal tissues and articulatory system.

2 There is no such thing as an intrinsically bad occlusal contact, only an intolerable number of times to parafunction on it.

3 The patient's occlusion should be recorded, before any treatment is started.

4 Compare the patient's occlusion against the benchmark of ideal occlusion.

5 A simple, two dimensional means of recording the patient's occlusion before, during and after treatment is an aid to good occlusal practice.

6 The conformative approach is the safest way of ensuring that the occlusion of a restoration does not have potentially harmful consequences.

7 Ensuring that the occlusion conforms (to the patient's pre-treatment state) is a product of examination, design, execution and checking (EDEC)

8 The 'reorganised approach' involves firstly the establishment of a 'more ideal' occlusion in the patient's pretreatment teeth or provisional restorations; and then adhering to that design using the techniques of the 'conformative approach'

9. An 'ideal occlusion' in removable prosthodontics is one which reduced de-stabilising forces

10. The occlusal objective of orthodontic treatment is not clear, but a large discrepancy between centric occlusion and centric relation should not be an outcome of treatment

11. An 'orthodontic' examination of the occlusion should include: the dynamic occlusion; and the jaw relationship in which the patient has centric occlusion

12. The occlusion of periodontally compromised teeth should be designed to reduce the forces to be within the adaptive capabilities of the damaged periodontia

13. Good occlusal practice in children is determined by the needs of the developing occlusion, consequentially 'restoration at all costs' may not be the best policy.

14. Not all tooth surface loss needs treatment, but effective monitoring is essential

15. Dento-alveolar compensation has often occured in patients exibiting marked tooth surface loss.

16. The occlusal prescription of an implant supported restoration needs to take account of the features of osseointegration

17. The occlusion should be planned before implants are placed 